\title{
A Post Hoc Holter ECG Analysis of Olodaterol and Formoterol in Moderate-to-Very-Severe COPD
}

This article was published in the following Dove Press journal: International Journal of Chronic Obstructive Pulmonary Disease

\author{
Stefan Andreas (D) ${ }^{1,2}$ \\ Ulrich Bothner ${ }^{3}$ \\ Alberto de la $\mathrm{Hoz}^{3}$ \\ Isabel Kloer ${ }^{3}$ \\ Matthias Trampisch ${ }^{3}$ \\ Peter Alter $\mathbb{1}^{4}$ \\ 'Department of Cardiology and \\ Pneumology, University Medical Center \\ Göttingen, Göttingen, Germany; \\ ${ }^{2}$ LungClinic Immenhausen, Immenhausen, \\ Germany, Member of the German Center \\ for Lung Research (DZL); ${ }^{3}$ Boehringer \\ Ingelheim International $\mathrm{GmbH}$, Ingelheim \\ am Rhein, Germany; ${ }^{4}$ Department of \\ Medicine, Pulmonary and Critical Care \\ Medicine, Philipps University of Marburg \\ (UMR), Marburg, Germany, Member of \\ the German Center for Lung \\ Research (DZL)
}

Correspondence: Stefan Andreas Department of Cardiology and Pneumology University Medical Center Göttingen, Robert-Koch-Str. 40, Göttingen, Germany Tel +490567350 I I I I2

Fax +49 05673-50 I- I I0 I Email stefan.andreas@med.uni-goettingen. de
Background: Patients with chronic obstructive pulmonary disease (COPD) are at risk of developing cardiac arrhythmias and elevated heart rate. A theoretical mechanistic association based on the interaction of long-acting $\beta_{2}$-agonists (LABAs) with adrenoreceptors in the heart and vasculature is assumed as a potential class-related risk. Therefore, we performed a pooled analysis of Holter electrocardiogram (ECG) data from four 48-week, randomized, double-blind, placebo-controlled, parallel-group, Phase III clinical trials evaluating olodaterol $(5 \mu \mathrm{g}$ or $10 \mu \mathrm{g})$ or formoterol $(12 \mu \mathrm{g})$ versus placebo.

Methods: We analyzed Holter ECG data from a representative subset of 775 patients with Global Initiative for Chronic Obstructive Lung Disease stage 2-4 COPD from four studies (1222.11-14) assessing olodaterol (5 $\mu \mathrm{g}$ and $10 \mu \mathrm{g})$ and formoterol (12 $\mu \mathrm{g})$ versus placebo. Results: No statistically significant $(\mathrm{P}>0.3)$ or clinically relevant differences in the shift from baseline of premature supraventricular or ventricular beats were observed among the active treatment and the placebo groups. Minor and transient differences were observed in the adjusted mean heart rate from baseline during treatment in all groups. There was a numerically small but statistically significant increase for formoterol at Week 24, olodaterol $5 \mu \mathrm{g}$ at Weeks 12 and 40, and olodaterol $10 \mu \mathrm{g}$ at Week 40 (all less than 3.0 beats per minute). Mean heart rates returned to a statistically non-significant change at Week 48 for all treatment groups. No increase in major adverse cardiovascular events was observed. Conclusion: Treatment with olodaterol or formoterol is not associated with arrhythmias or a persistent increase in heart rate as assessed by Holter ECG in patients with COPD.

Trial Registration: ClinicalTrials.gov identifiers: NCT00782210 (1222.11); NCT00782509 (1222.12); NCT00793624 (1222.13); NCT00796653 (1222.14).

Keywords: olodaterol, formoterol, arrhythmia, Holter ECG, heart rate

\section{Plain Language Summary}

The present study aimed to explore whether two drugs (olodaterol and formoterol) commonly used for the treatment of chronic obstructive pulmonary disease (COPD) are associated with irregular heartbeats (arrhythmias) or changes in heart rate. This consideration is based on the fact that these drugs belong to a class called long-acting $\beta_{2}$-agonists (LABAs). These drugs have the potential to affect heart rhythm in individuals with COPD, which could be detrimental to their health. To better understand this, the heart rhythm of a group of patients taking olodaterol and formoterol in four clinical trials was monitored at pre-specified time points during the study using a 24-hour wearable Holter electrocardiogram recorder. Combined data from these studies show that treatment with olodaterol and formoterol did not cause adverse changes in heart rhythm. Small, temporary increases in heart rate were seen 
with both drugs, but these were not persistent at the end of the 48-week observation period. Therefore, we conclude that treatment with olodaterol or formoterol is not associated with arrhythmias or persistent increases in heart rate.

\section{Background}

Chronic obstructive pulmonary disease (COPD) is associated with cardiovascular (CV) comorbidities, hospitalization and death. $^{1,2}$ These comorbidities include thromboembolic disorders, myocardial ischemia and infarction, or stroke with a substantially higher prevalence in patients with COPD compared with healthy individuals. ${ }^{1,3-5}$ Other concerns for COPD patients include increased resting heart rate and cardiac arrhythmias (supraventricular and ventricular arrhythmias, and atrial fibrillation), which are risk markers for heart disease and impaired prognosis. ${ }^{6-9}$ Given this background, the safety of long-acting $\beta_{2}$-agonists (LABAs) in this setting should be evaluated. As a drug class, LABAs have the potential to affect cardiac characteristics such as heart rate and rhythm disturbances. ${ }^{10,11}$ These effects are potentially mediated by stimulation of $\beta_{2}$-adrenoreceptors (ARs) in the atria, ventricles and peripheral vasculature and are opposite to those of $\beta$ blockers used to treat cardiac arrhythmias. ${ }^{10,12-14}$ Indeed, in the human heart, $\beta_{1}$ and $\beta_{2}$-ARs coexist in both atria and in both ventricles with a $\beta_{1} / \beta_{2}$ ratio of approximately $65 / 35 \%$ in the atria and $75 / 25 \%$ in the ventricles. ${ }^{9}$

Olodaterol is a more recently developed, once-daily LABA designed with the aim of improving $\beta_{2}$-AR selectivity and intrinsic activity. ${ }^{15}$ It is structurally distinct from formoterol and salmeterol. All $\beta$-agonist compounds are racemates, with the $(R)$-enantiomer being the active component and the $(S)$-enantiomer being inactive at therapeutic concentrations. $^{15-17}$ In vitro studies suggest that the $(S)$ enantiomer may induce tachyphylaxis or receptor desensitization. ${ }^{15}$ Thus, pure $(R, R)-\beta$-agonists like olodaterol provide bronchodilation at lower doses than the racemate, potentially allowing for fewer $\beta_{2}$-AR-mediated side effects. $^{15}$

Although a previous analysis showed that long-term administration of olodaterol or formoterol does not adversely influence heart rate or blood pressure in patients with moderate-to-severe $\mathrm{COPD},{ }^{13}$ there is a lack of data on long-term effects of LABAs on heart rhythm. To address this and test the hypothesis that a greater selectivity of olodaterol may translate into lower cardiac side effects, we conducted an extensive analysis of Holter electrocardiogram (ECG) data collected from subsets of patients taking part in four 48-week, randomized, double- blind, placebo-controlled, parallel-group, Phase III trials assessing olodaterol $5 \mu \mathrm{g}$ or $10 \mu \mathrm{g}$, or formoterol $12 \mu \mathrm{g}$, versus placebo in patients with Global Initiative for Chronic Obstructive Lung Disease (GOLD) stage 2-4 (ie moderate-to-very-severe) COPD. Here, we report the findings from a pooled analysis of studies 1222.11-14.

\section{Methods}

\section{Study Design}

Studies 1222.11 and 1222.12 were 48 -week, randomized, double-blind, placebo-controlled, parallel-group, Phase III replicate trials. Detailed study methods have been published previously. ${ }^{18}$ Overall, 1,266 patients with moderateto-very-severe COPD (GOLD stage 2-4) were treated with olodaterol $5 \mu \mathrm{g}$, olodaterol $10 \mu \mathrm{g}$ or placebo delivered once daily via Respimat ${ }^{\circledR}$ Soft Mist $^{\mathrm{TM}}$ inhaler (SMI). ${ }^{18}$ The co-primary efficacy endpoints were forced expiratory volume in 1 second $\left(\mathrm{FEV}_{1}\right)$ area under the curve 3 hours post-dose $\left(\mathrm{AUC}_{0-3}\right)$ response (change from baseline) and trough $\mathrm{FEV}_{1}$ response (measured as pre-dose $\mathrm{FEV}_{1}$ ) at 12 weeks. $^{18}$

Studies 1222.13 and 1222.14 were 48-week, randomized, double-blind, placebo-controlled, parallel-group, Phase III trials. Detailed study methods have been published previously. ${ }^{19}$ Overall, 1,838 patients with moderateto-very-severe COPD (GOLD stage 2-4) were treated with olodaterol (5 or $10 \mu \mathrm{g}$ ) once daily (via SMI), $12 \mu \mathrm{g}$ formoterol twice daily (via Aerolizer ${ }^{\circledR}$ dry powder inhaler [DPI]) or placebo (SMI/DPI, double-dummy). ${ }^{19}$ The coprimary efficacy endpoints were $\mathrm{FEV}_{1} \mathrm{AUC}_{0-3}$ response, trough $\mathrm{FEV}_{1}$ response and Mahler transition dyspnea index after 24 weeks of treatment. ${ }^{19}$

All of the four studies, except for the additional comparison with formoterol in studies 1222.13 and 1222.14, had an identical design, thereby enabling complete pooling of the safety data.

Inclusion and exclusion criteria were also the same for the four studies. Patients with COPD aged $\geq 40$ with a smoking history of $>10$ pack-years and a postbronchodilator $\mathrm{FEV}_{1}$ of $<80 \%$ predicted were included. Patients were excluded if they had a significant disease other than COPD, a history of asthma, of myocardial infarction within 1 year of screening, unstable or lifethreatening cardiac arrhythmia, life-threatening pulmonary obstruction, if they regularly used daytime oxygen therapy or were currently in, or had recently completed, a pulmonary rehabilitation program. 


\section{Sub-Analyses on Holter ECGs}

In each study, 24-hour Holter monitoring was performed in a subset of patients at selected sites who were capable of and trained to handle centralized Holter ECG monitoring. All patients at selected sites were invited to participate in this sub-study. Holter monitoring was performed in patients giving informed consent to participate in the sub-study and capable of carrying and returning the equipment after 24 hours. Two hundred patients (50 patients per treatment group) participated in studies 1222.11/12/13 and 175 patients in study 1222.14. Sites were provided with standard equipment by the sponsor (12-Lead Mortara H12+ Digital Holter Recorder, eResearchTechnology, Inc, Philadelphia, USA). Holter ECG recordings were transferred to the central vendor (eResearchTechnology, Inc) for review by a cardiologist before data upload to the study database. Holter monitoring was to be performed in a subset of up to 800 patients prior to randomization at Visit 2 (baseline), and during randomized treatment at Visit 5 (Day 85, Week 12), Visit 7 (Day 169, Week 24), Visit 9 (Day 281, Week 40) and Visit 10 (Day 337, Week 48).

\section{Statistical Analysis}

The 24-hour Holter ECG records were evaluated for mean heart rate, as well as the number of supraventricular premature beats (SVPBs) and ventricular premature beats (VPBs) in a pre-specified analysis. Increase or decrease in SVPBs and VPBs from baseline on treatment was established using two-way shift tables. Shifts were defined based on predefined cut-offs with the following categories: $<10, \geq 10$ to $<30, \geq 30$ to $<50, \geq 50$ to $<100, \geq 100$ to $<500$, $\geq 500$ to $<1000, \geq 1000$ to $<2000$ and $\geq 2000$ premature beats in 24 hours. The number of individuals who moved from one category to another (increase, decrease or no change) was then calculated. Categories assigned at baseline and at Weeks 12, 24, 40 and 48 were compared to give shifts in SVPBs and VPBs. The shift proportions were tested for significant differences between treatments and differences in the frequency of shifts (increase, decrease or unchanged from baseline) were evaluated between treatments using Chi-squared testing. Additional data were collected across all studies on the heart rates measured by the Holter ECGs. Adjusted mean changes from baseline and treatment differences for the 24-hour Holter ECG mean heart rates were analyzed using a mixed-effect model repeat measurement with fixed effects for treatment, visit, treatment-by-visit interaction, baseline and baseline- by-visit interaction. Patient is considered a random variable and an unstructured covariance structure was used. $\mathrm{P}<0.05$ was considered a significant difference for all post hoc statistical analyses at an alpha level of 0.05 .

\section{Results}

\section{Baseline Demographics}

In total, 775 patients were included in Holter ECG monitoring subsets. The patient characteristics of all studies have been described previously. ${ }^{18,19}$ Baseline demographics for the subset of patients included in the Holter ECG examinations are displayed in Table 1 and were generally representative of the whole study populations. ${ }^{20}$ The subset consisted of $68.4 \%$ males, with a mean age of 63.1 years. When classified by GOLD, the majority of patients were GOLD stage $2(52.3 \%)$ or GOLD stage 3 (39.5\%), with $7.9 \%$ classified as GOLD stage 4 . At baseline, $13.6 \%$ of patients had documented pre-existing conditions of cardiac arrhythmia and $14.5 \%$ of patients had ischemic heart disease. With regard to CV risk, the Holter subset was representative of the full study population ${ }^{20}$ in relation to their $\mathrm{CV}$ medication presented at baseline. However, the Holter subset had a slightly higher incidence of cardiac arrhythmia compared with the full study population (Supplementary Table 1). Overall, the treatment groups were well balanced; however, a lower percentage of patients $(48.8 \%)$ in the formoterol $12 \mu \mathrm{g}$ group were affected by $\mathrm{CV}$ disease at baseline compared with the other treatment groups $(62.8 \%$ for the olodaterol $10 \mu \mathrm{g}$ group, $62.6 \%$ for the olodaterol $5 \mu$ g group and $57.1 \%$ for the placebo group; Table 1).

\section{Holter ECG Data Shift in SVPB}

Neither medically relevant nor statistically significant differences were observed in the SVPB shifts (ie, proportion of patients whose SVPB increased or decreased from baseline) with the active treatments - olodaterol $5 \mu \mathrm{g}$, olodaterol $10 \mu \mathrm{g}$ and formoterol $12 \mu \mathrm{g}$ - compared with placebo (p-values $=0.3087,0.9024,0.4355$ and 0.4857 for Week 12, Week 24, Week 40 and Week 48, respectively, Chisquared test; Figure 1). At Week 48, 38 (23.3\%), 43 $(25.3 \%), 32(18.5 \%)$ and $16(26.7 \%)$ patients had an increase in SVPBs from baseline, and $47(28.8 \%), 51$ $(30.0 \%), \quad 65(37.6 \%)$ and $19(31.7 \%)$ patients had a decrease from baseline with placebo, olodaterol $5 \mu \mathrm{g}$, olodaterol $10 \mu \mathrm{g}$ and formoterol $12 \mu \mathrm{g}$, respectively. 
Table I Baseline Demographics of Holter ECG Subgroups (I222.11, 1222.12, 1222.13 and I222.14)

\begin{tabular}{|c|c|c|c|c|}
\hline Characteristics & $\begin{array}{l}\text { Placebo } \\
(\mathrm{N}=226)\end{array}$ & $\begin{array}{l}\text { Olo } 5 \mu g \\
(N=235)\end{array}$ & $\begin{array}{l}\text { Olo } 10 \mu g \\
(N=234)\end{array}$ & $\begin{array}{l}\text { Form } 12 \mu g \\
(\mathrm{~N}=80)\end{array}$ \\
\hline Male, n (\%) & $150(66.4)$ & $163(69.4)$ & $157(67.1)$ & $60(75.0)$ \\
\hline Age, mean (SD), years & $63.9(7.9)$ & $62.8(8.5)$ & $62.8(8.6)$ & $62.5(8.8)$ \\
\hline \multicolumn{5}{|l|}{ Smoking status, n (\%) } \\
\hline Ex-smoker & $125(55.3)$ & $|3|(55.7)$ & $128(54.7)$ & $46(57.5)$ \\
\hline Current smoker & I0I (44.7) & $104(44.3)$ & $106(45.3)$ & $34(42.5)$ \\
\hline BMI, mean (SD), $\mathrm{kg} / \mathrm{m}^{2}$ & $26.2(6.4)$ & $27.4(6.8)$ & $26.2(6.4)$ & $24.0(5.2)$ \\
\hline $\mathrm{FEV}_{1} \%$ predicted normal, mean (SD) & $46.4(15.0)$ & $44.6(14.4)$ & $44.4(15.3)$ & $44.3(15.1)$ \\
\hline \multicolumn{5}{|l|}{ GOLD stage, n (\%) } \\
\hline $\mathrm{I}(\geq 80 \%)$ & I $(0.4)$ & I (0.4) & I $(0.4)$ & $0(0.0)$ \\
\hline $2(50 \%$ to $<80 \%)$ & I $32(58.4)$ & $119(50.6)$ & II 4 (48.7) & $40(50.0)$ \\
\hline $3(30 \%$ to $<50 \%)$ & $74(32.7)$ & $98(41.7)$ & $102(43.6)$ & $32(40.0)$ \\
\hline $4(<30 \%)$ & $19(8.4)$ & $17(7.2)$ & $17(7.3)$ & $8(10.0)$ \\
\hline Holter heart rate, mean (SD) & $81.0(9.7)$ & $81.1(10.2)$ & $82.2(11.4)$ & $82.2(11.7)$ \\
\hline Cardiovascular disease, n (\%) & $129(57.1)$ & 147 (62.6) & $147(62.8)$ & $39(48.8)$ \\
\hline Cardiac arrhythmia, n (\%) & $4 I(18.1)$ & $45(19.1)$ & $40(17.1)$ & $9(11.3)$ \\
\hline Tachyarrhythmia (tachycardia) & $21(9.3)$ & $23(9.8)$ & $21(9.0)$ & $3(3.8)$ \\
\hline Supraventricular tachyarrhythmia & $8(3.5)$ & $4(1.7)$ & $6(2.6)$ & $\mathrm{I}(\mathrm{I} .3)$ \\
\hline Atrial fibrillation or flutter & $7(3.1)$ & $3(1.3)$ & $4(1.7)$ & $0(0.0)$ \\
\hline Ventricular tachyarrhythmia (ventricular arrhythmia) & $13(5.8)$ & $18(7.7)$ & $17(7.3)$ & $\mathrm{I}(\mathrm{l} .3)$ \\
\hline Bradyarrhythmia (bradycardia) & $19(8.4)$ & $21(8.9)$ & $21(9.0)$ & $5(6.3)$ \\
\hline Ischemic heart disease ${ }^{\mathrm{a}}, \mathrm{n}(\%)$ & $28(12.4)$ & $35(14.9)$ & $42(17.9)$ & $7(8.8)$ \\
\hline Myocardial infarction ${ }^{\mathrm{b}}$ & II (4.9) & II (4.7) & II (4.7) & $3(3.8)$ \\
\hline Other ischemic heart disease (non-infarction) & $23(10.2)$ & $30(12.8)$ & $37(15.8)$ & $6(7.5)$ \\
\hline Cardiac failure, n (\%) & $6(2.7)$ & $5(2.1)$ & $9(3.8)$ & $\mathrm{I}(\mathrm{I} .3)$ \\
\hline Cerebrovascular disorders, n (\%) & $9(4.0)$ & $10(4.3)$ & II (4.7) & $\mathrm{I}(\mathrm{I} .3)$ \\
\hline Hypertension, n (\%) & $94(41.6)$ & $122(5 \mid .9)$ & $107(45.7)$ & $29(36.3)$ \\
\hline Diabetes mellitus, n (\%) & 27 (11.9) & $40(17.0)$ & $33(14.1)$ & $8(10.0)$ \\
\hline \multicolumn{5}{|l|}{ Cardiovascular medication, n (\%) } \\
\hline Any cardiovascular medication ${ }^{c}$ & $|5|(66.8)$ & $|7|(72.8)$ & I68 (7I.8) & $47(58.8)$ \\
\hline$\beta$-blockers & $34(15.0)$ & $35(14.9)$ & $24(10.3)$ & $5(6.3)$ \\
\hline Other cardiovascular medication ${ }^{d}$ & $15 \mid(66.8)$ & $170(72.3)$ & $165(70.5)$ & $46(57.5)$ \\
\hline \multicolumn{5}{|l|}{ Respiratory medications, n (\%) } \\
\hline SAMA & $56(24.8)$ & $49(20.9)$ & $52(22.2)$ & $17(21.3)$ \\
\hline LAMA & $67(29.6)$ & $67(28.5)$ & 7I (30.3) & $25(31.3)$ \\
\hline SABA & I $33(58.8)$ & $102(43.4)$ & $108(46.2)$ & $34(42.5)$ \\
\hline LABA & $93(4 \mid .2)$ & $136(57.9)$ & $|4|(60.3)$ & $40(50.0)$ \\
\hline ICS & $105(46.5)$ & II 0 (46.8) & II 0 (47.0) & $35(43.8)$ \\
\hline
\end{tabular}

ancludes angina pectoris, arteriosclerosis coronary artery, blood creatinine phosphokinase increase, coronary angioplasty, coronary arterial stent insertion, coronary artery bypass, coronary artery disease, ECG Twave abnormal, ECG Twave inversion, ischemic cardiomyopathy, myocardial infarction, myocardial ischemia and silent myocardial infarction; ' Includes conditions attributed to infarction, including blood creatinine phosphokinase increase, myocardial infarction and silent myocardial infarction; ' Includes $\beta$-blockers and other cardiovascular medication; ${ }^{\mathrm{d} A g e n t s ~ a c t i n g ~ o n ~ t h e ~ r e n i n-a n g i o t e n s i n ~ s y s t e m, ~ a n t i h y p e r t e n s i v e s, ~ a n t i t h r o m b o t i c ~ a g e n t s, ~ c a l c i u m ~ c h a n n e l ~ b l o c k e r s, ~ d i u r e t i c s, ~ l i p i d-m o d i f y i n g ~ a g e n t s, ~ o t h e r ~}$ cardiac therapy, peripheral vasodilators and vasoprotectives.

Abbreviations: BMI, body mass index; ECG, electrocardiogram; $\mathrm{FEV}_{1}$, forced expiratory volume in I second; Form, formoterol; GOLD, Global Initiative for Chronic Obstructive Lung Disease; ICS, inhaled corticosteroid; LABA, long-acting $\beta_{2}$-agonist; LAMA, long-acting muscarinic antagonist; Olo, olodaterol; SABA, short-acting $\beta_{2}$ agonist; SAMA, short-acting muscarinic antagonist; SD, standard deviation. 
A

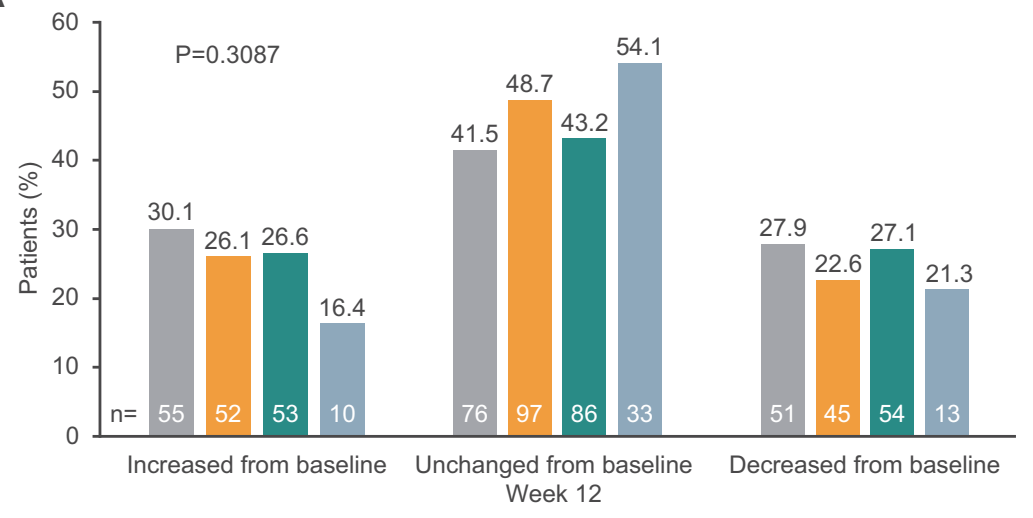

Placebo $(n=183)$ Olo 5 ug $(n=199)$

- Olo $10 \mu \mathrm{g}(\mathrm{n}=199)$

Form $12 \mu \mathrm{g}(\mathrm{n}=61)$

B

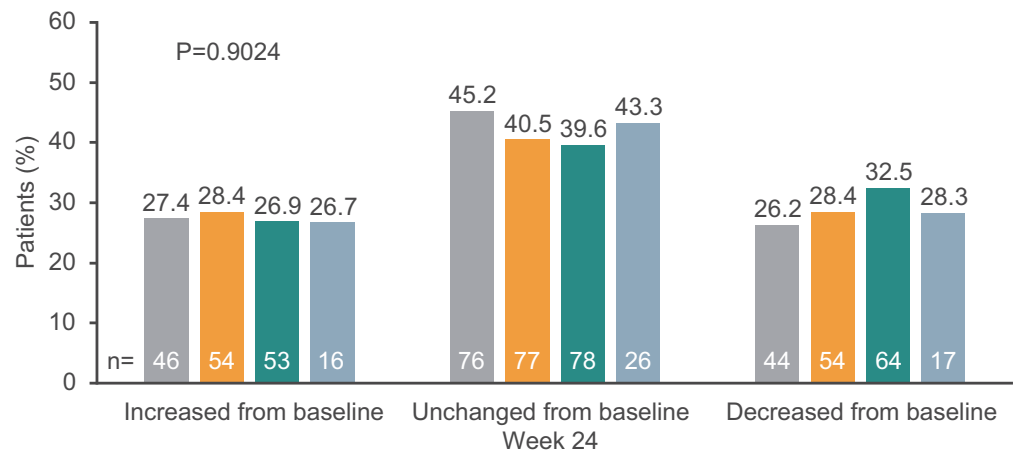

C

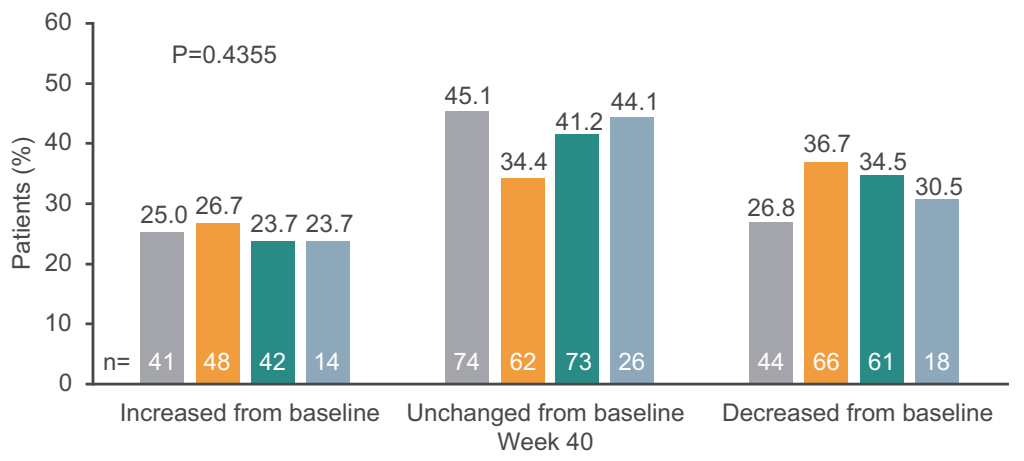

Placebo $(n=168)$

- Olo $5 \mu \mathrm{g}(\mathrm{n}=190)$

- Olo $10 \mu \mathrm{g}(\mathrm{n}=197)$

Form $12 \mu \mathrm{g}(\mathrm{n}=60)$

D

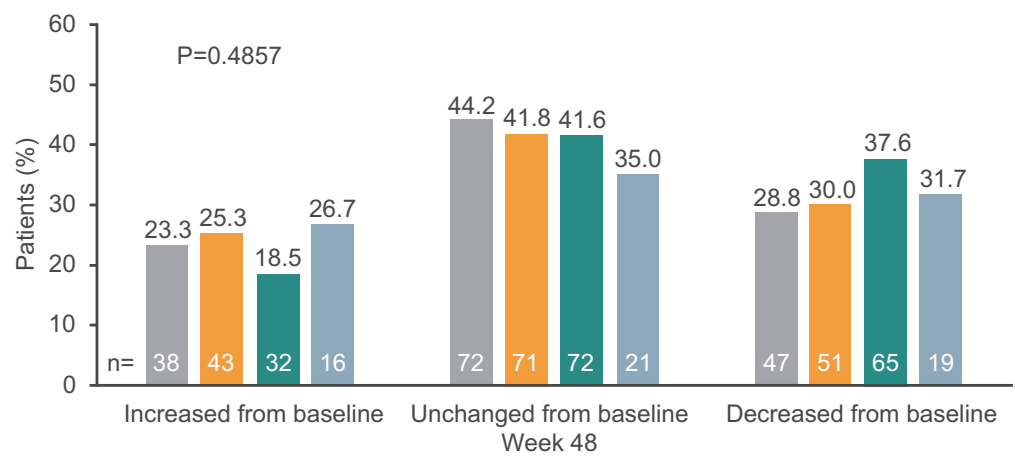

Placebo $(n=164)$

Olo $5 \mu \mathrm{g}(\mathrm{n}=180)$

- Olo $10 \mu \mathrm{g}(\mathrm{n}=177)$

Form $12 \mu \mathrm{g}(\mathrm{n}=59)$

Week 40 
A

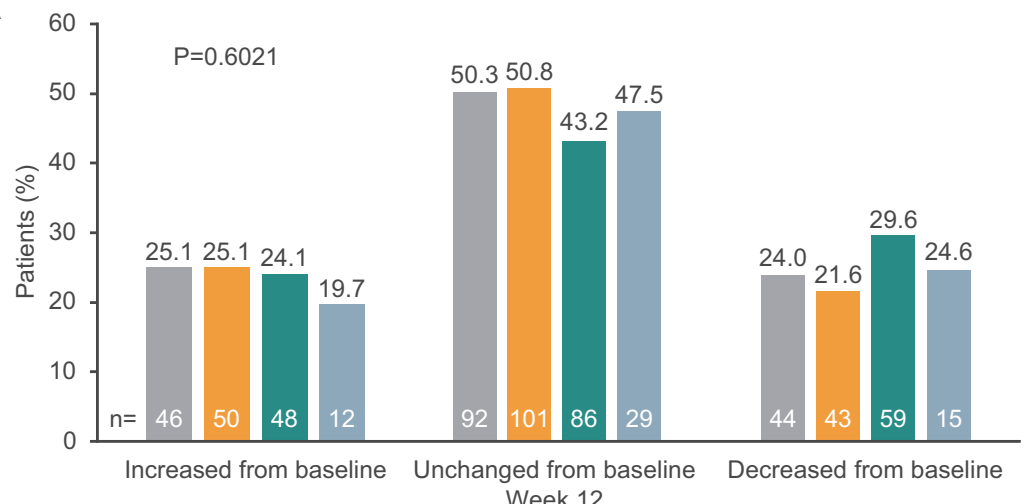

Placebo $(\mathrm{n}=183)$

- Olo $5 \mu \mathrm{g}(\mathrm{n}=199)$

- Olo $10 \mu \mathrm{g}(\mathrm{n}=199)$

Form $12 \mu \mathrm{g}(\mathrm{n}=61)$

B

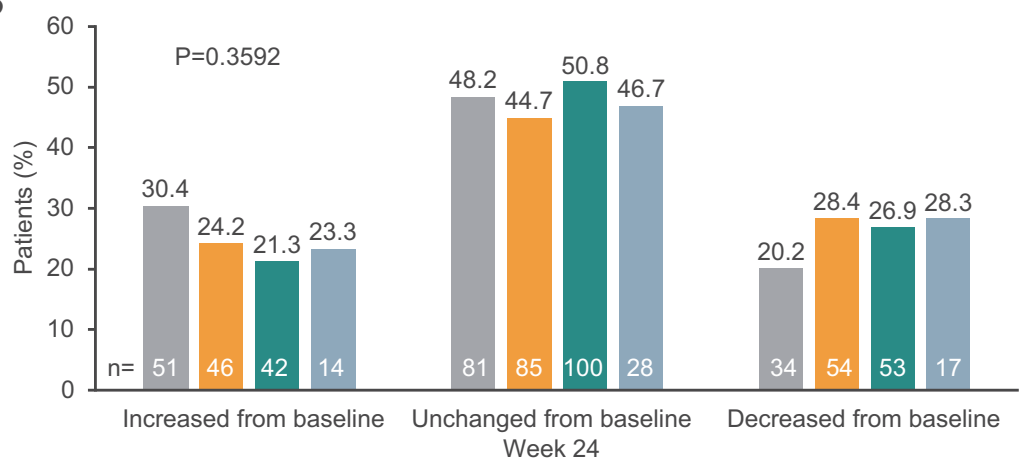

Placebo $(n=168)$

- Olo $5 \mu \mathrm{g}(\mathrm{n}=190)$

- Olo $10 \mu \mathrm{g}(\mathrm{n}=197)$

Form $12 \mu \mathrm{g}(\mathrm{n}=60)$

\section{C}

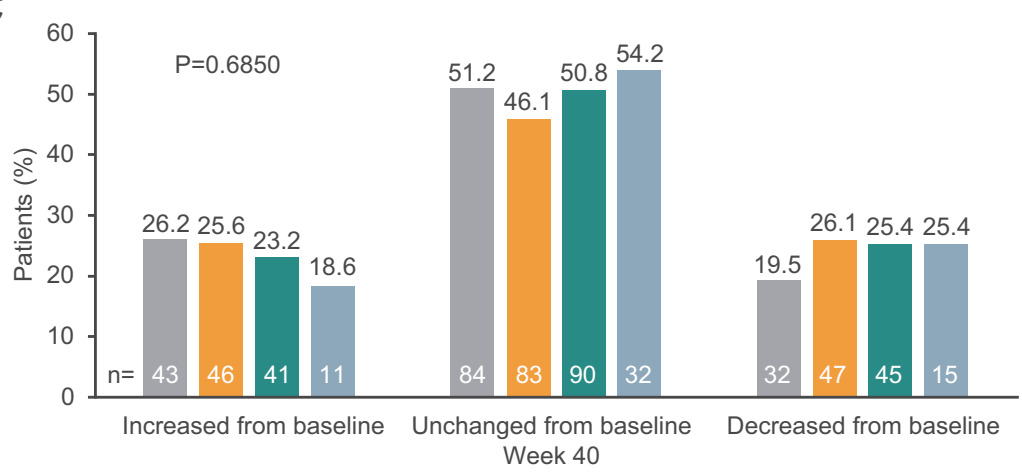

Placebo $(n=164)$

- Olo $5 \mu \mathrm{g}(\mathrm{n}=180)$

- Olo $10 \mu \mathrm{g}(\mathrm{n}=177)$

Form $12 \mu \mathrm{g}(\mathrm{n}=59)$

D

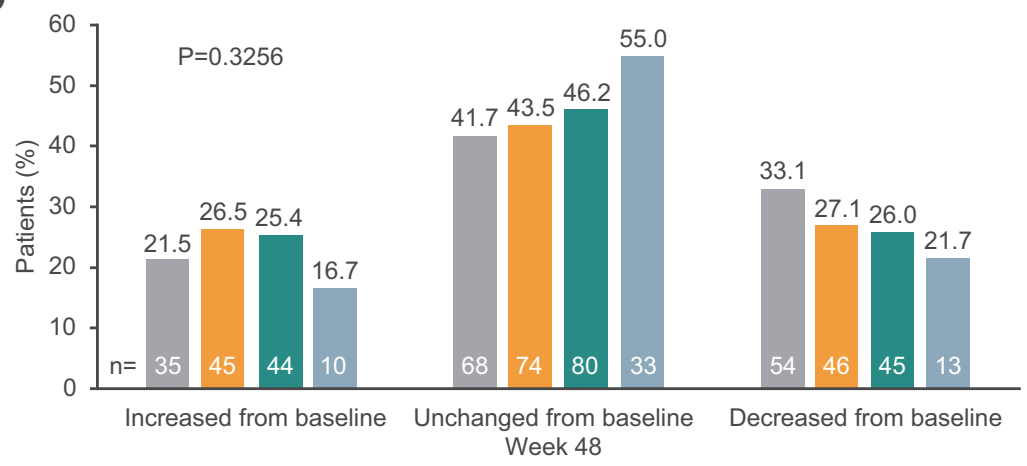

Placebo $(n=163)$

- Olo $5 \mu \mathrm{g}(\mathrm{n}=170)$

- Olo $10 \mu \mathrm{g}(\mathrm{n}=173)$

- Form $12 \mu \mathrm{g}(\mathrm{n}=60)$

Figure 2 Shifts in VPB: olodaterol and formoterol vs placebo at (A) Week 12, (B) Week 24, (C) Week 40 and (D) Week 48.

P-values for overall differences between category of change and category of treatment calculated by Chi-squared frequency tests; Numbers above the bars are \% of patients whereas numbers within the bars are number of patients.

Abbreviations: Form, formoterol; Olo, olodaterol; VPB, ventricular premature beats. 


\section{Shift in VPB}

Neither medically relevant nor statistically significant differences were observed in the VPB shifts with the active treatments - olodaterol $5 \mu \mathrm{g}$, olodaterol $10 \mu \mathrm{g}$ and formoterol $12 \mu \mathrm{g}$-compared with placebo ( $\mathrm{p}$-values $=0.6021$, $0.3592,0.6850$ and 0.3256 for Week 12, Week 24, Week 40 and Week 48, respectively, Chi-squared test; Figure 2). At Week 48, 35 (21.5\%), 45 (26.5\%), 44 $(25.4 \%)$ and $10(16.7 \%)$ patients had an increase in VPBs from baseline, and 54 (33.1\%), 46 (27.1\%), 45 $(26.0 \%)$ and $13(21.7 \%)$ had a decrease from baseline with placebo, olodaterol $5 \mu \mathrm{g}$, olodaterol $10 \mu \mathrm{g}$ and formoterol $12 \mu \mathrm{g}$, respectively.

\section{Holter ECG Heart Rate Data}

Overall, numerically small and not clinically relevant differences in the mean heart rate from baseline were observed during treatment. The mean heart rate at baseline was similar between the treatment groups ( 81.0 beats per minute [bpm] for placebo, $81.1 \mathrm{bpm}$ for olodaterol $5 \mu \mathrm{g}, 82.2 \mathrm{bpm}$ for olodaterol $10 \mu \mathrm{g}$ and $82.2 \mathrm{bpm}$ for formoterol $12 \mu \mathrm{g}$; Figure 3A). During the long-term treatment, there was a numerically small but statistically significant increase with formoterol at Week $24(+2.9 \mathrm{bpm} ; \mathrm{p}=0.0022)$, olodaterol $5 \mu \mathrm{g}$ at Week $12(+1.1 \mathrm{bpm} ; \mathrm{p}=0.0186)$ and Week 40 $(+1.6 \mathrm{bpm} ; \mathrm{p}=0.0146)$, and olodaterol $10 \mu \mathrm{g}$ at Week 40 $(+1.7$ bpm, $\mathrm{p}=0.0068)$ (Figure 3B). At Week 48, no significant changes from baseline were observed for any treatment.

\section{Safety (Adverse Events)}

During the 48 weeks of treatment, there was no increase in the number of patients with major adverse $\mathrm{CV}$ events (MACE; including cardiac disorder, vascular disorder, myocardial infarction, stroke, sudden death, cardiac death and sudden cardiac death) or fatal MACE with olodaterol (5 $\mu \mathrm{g}$ or $10 \mu \mathrm{g}$ ) or formoterol compared with placebo (MACE: 5 [2.1\%], 8 [3.4\%], 2 [2.5\%] and 9 [4.0\%], respectively; fatal MACE [including death unknown]: 2 $[0.9 \%], 1[0.4 \%], 1[1.3 \%]$ and $2[0.9 \%]$, respectively) (Table 2). Incidence of cardiac arrhythmia was similar across treatments. The number of patients with cardiac arrhythmia in the olodaterol $(5 \mu \mathrm{g}$ or $10 \mu \mathrm{g})$ or formoterol groups was similar compared with the placebo group (supraventricular tachyarrhythmia: 4 [1.7\%], 5 [2.1\%], 4 [5.0\%] and 9 [4.0\%], respectively; atrial fibrillation or flutter: 2 [0.9\%], 3 [1.3\%], 1 [1.3\%] and 6 [2.7\%], respectively; ventricular tachyarrhythmia: 15 [6.4\%], 12 [5.1\%], 7 [8.8\%] and $8[3.5 \%]$ ) (Table 2).

\section{Discussion}

Airway obstruction and lung hyperinflation are characteristics of COPD. ${ }^{21}$ Previous echocardiography data show that lung hyperinflation leads to impaired left ventricular diastolic filling and global right heart dysfunction in patients with COPD. ${ }^{21-23}$ These mechanisms, alongside hypoxia, chemoreflexes and reduced baroreflexes, may cause neurohumoral activation and increased heart rate. ${ }^{24}$ Bronchodilators exhibit

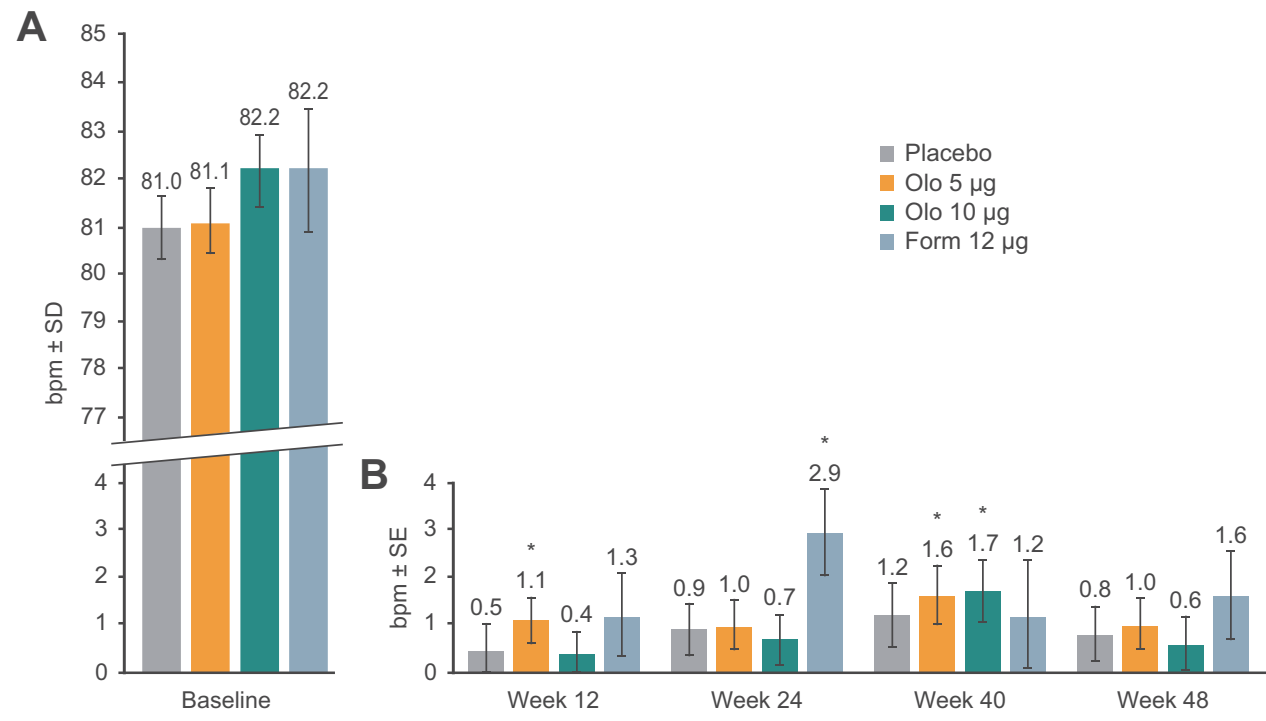

Figure 3 Unadjusted baseline heart rate $(\mathbf{A})$ and adjusted mean change in heart rate from baseline (B): olodaterol and formoterol vs placebo during treatment. $* \mathrm{P}<0.05$. P-values are for adjusted mean change from baseline.

Abbreviations: bpm, beats per minute; Form, formoterol; Olo, olodaterol; SD, standard deviation; SE, standard error. 
Table 2 Adverse Events of Holter ECG Subgroups

\begin{tabular}{|c|c|c|c|c|}
\hline Patients, n (\%) & Placebo $(\mathrm{N}=226)$ & 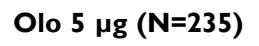 & Olo $10 \mu g(N=234)$ & Form I $2 \mu g(N=80)$ \\
\hline \multicolumn{5}{|l|}{ Cardiac arrhythmia } \\
\hline Supraventricular tachyarrhythmia & $9(4.0)$ & $4(1.7)$ & $5(2.1)$ & $4(5.0)$ \\
\hline Atrial fibrillation or flutter & $6(2.7)$ & $2(0.9)$ & $3(1.3)$ & $\mathrm{I}(\mathrm{l} .3)$ \\
\hline Ventricular tachyarrhythmia & $8(3.5)$ & $15(6.4)$ & $12(5.1)$ & $7(8.8)$ \\
\hline \multicolumn{5}{|l|}{ Ischemic heart disease } \\
\hline Myocardial infarction & $5(2.2)$ & $2(0.9)$ & $8(3.4)$ & I (I.3) \\
\hline Other ischemic heart disease (non-infarction) & $4(1.8)$ & $3(1.3)$ & $6(2.6)$ & $0(0.0)$ \\
\hline Cardiac failure & $\mathrm{I}(0.4)$ & $\mathrm{I}(0.4)$ & $\mathrm{I}(0.4)$ & $\mathrm{I}(\mathrm{l} .3)$ \\
\hline \multicolumn{5}{|l|}{ Cerebrovascular disorders } \\
\hline Hemorrhagic & $\mathrm{I}(0.4)$ & I $(0.4)$ & $0(0.0)$ & $0(0.0)$ \\
\hline Ischemic & $3(1.3)$ & $3(1.3)$ & $2(0.9)$ & $0(0.0)$ \\
\hline MACE & $9(4.0)$ & $5(2.1)$ & $8(3.4)$ & $2(2.5)$ \\
\hline Fatal MACE (including death unknown) & $2(0.9)$ & $2(0.9)$ & I $(0.4)$ & $\mathrm{I}(\mathrm{l} .3)$ \\
\hline
\end{tabular}

Abbreviations: ECG, electrocardiogram; Form, formoterol; MACE, major adverse cardiovascular events (including cardiac disorder, vascular disorders, myocardial infarction, stroke, sudden death, cardiac death and sudden cardiac death); Olo, olodaterol.

beneficial effects on daily physical activity, endurance time, hyperinflation and ventricular filling. ${ }^{23,25}$ Consequently, they have the potential to improve cardiac function ${ }^{26}$ and reduce neurohumoral activation and heart rate. ${ }^{24}$

However, there is an ongoing debate about the long-term cardiac safety of cardioactive inhaled pulmonary drugs, such as LABAs, in patients with COPD and concomitant CV morbidities. ${ }^{27}$ Indeed, LABAs have the potential to induce increased heart rate through stimulation of $\beta_{2}$-ARs in the heart. ${ }^{9}$ For example, salmeterol has been associated with an acute heart rate increase but its cardiac safety has been demonstrated with a longer treatment duration. ${ }^{9}$ Given this background and that increased heart rate is associated with a higher mortality in patients with COPD, it was of interest to investigate the effect of the LABAs olodaterol and formoterol on cardiac parameters using Holter ECG monitoring. Continuous Holter ECGs are commonly used to diagnose and monitor cardiac arrhythmias, ${ }^{28}$ and the European Society of Cardiology guidelines recommend $24-48$ hours' continuous Holter recording when arrhythmia is known or suspected to occur. $^{29}$

Olodaterol is a once-daily LABA designed to improve $\beta_{2}$-AR selectivity and intrinsic activity compared with formoterol and salmeterol. ${ }^{15,30}$ Phase III trials show that olodaterol $5 \mu \mathrm{g}$ administered using an SMI induces the fast onset of bronchodilation with significant lung function improvements up to 48 weeks in patients with moderateto-very-severe COPD. ${ }^{15}$
This paper reports the results of an analysis of Holter ECG data from a subset of patients receiving either olodaterol $5 \mu \mathrm{g}$ or $10 \mu \mathrm{g}$, formoterol $12 \mu \mathrm{g}$ or placebo in four Phase III trials (1222.11-14). The purpose of the analysis was to examine the cardiac safety of two LABAs and determine whether the structural difference between olodaterol and formoterol results in an observable difference in the safety profiles of the drugs.

Our analysis included a large cohort of 775 patients. Treatment groups were well balanced but there was a lower percentage of patients (48.8\%) in the formoterol $12 \mu \mathrm{g}$ group affected by $\mathrm{CV}$ disease at baseline compared with the other treatment groups ( $62.8 \%$ for the olodaterol $10 \mu$ g group, $62.6 \%$ for the olodaterol $5 \mu \mathrm{g}$ group and $57.1 \%$ for the placebo group; Table 1). This may mean that any effect of formoterol on Holter ECG parameters was less likely to occur in this group compared with the potentially higher risk inherent in the olodaterol groups. However, the analysis shows that there was no evidence of a pro-arrhythmic SVPB and VPB effect for olodaterol $5 \mu \mathrm{g}$ or $10 \mu \mathrm{g}$, or formoterol $12 \mu \mathrm{g}$, compared with placebo. With respect to heart rate, only small and transient changes were observed over the 48 weeks of treatment for all treatment groups. It remains uncertain whether these small increases in the mean heart rate, which were statistically significant with formoterol at Week 24, olodaterol $5 \mu \mathrm{g}$ at Week 12 and Week 40, and olodaterol $10 \mu \mathrm{g}$ at Week 40, should be attributed to the direct pharmacologic effects of bronchodilators or to increased physical activity following bronchodilation therapy or both. ${ }^{31}$ A similar trend was observed for placebo over the 48 
weeks of treatment and this might indicate a progression of the disease; however, the observation of longer treatment periods may allow the drawing of stronger conclusions. We also found no increase in the number of patients with fatal or major adverse $\mathrm{CV}$ events or changes in heart rhythm with any active drug compared with placebo. These results are in line with previous studies demonstrating the cardiac safety of olodaterol and formoterol in patients with COPD. ${ }^{13,32}$

Neither the structural differences between olodaterol and formoterol nor the difference in baseline $\mathrm{CV}$ disease seems to have influenced the analysis outcome. This may not be surprising given the likely low systemic bioavailability of the inhaled drugs. ${ }^{33}$ Moreover, the high selectivity, high intrinsic activity and enantiopurity of olodaterol allow lower microgram dose amounts compared with other LABAs. ${ }^{18,34}$ As a consequence of lower doses, less active drug is available for a systemic distribution. Indeed, pharmacokinetic evaluation shows that inhaled olodaterol plasma concentrations decline quickly (37-56\% of maximum measured concentration at 6 hours on regular treatment following inhalation of 10 and $20 \mu \mathrm{g}$ olodaterol); furthermore, trough plasma concentrations were mostly below the limit of quantification $(2.0 \mathrm{pg} / \mathrm{mL})$ following inhalation of olodaterol $5 \mu \mathrm{g}$ once daily and were quantifiable in only one-third of patients after olodaterol $5 \mu \mathrm{g}$ twice daily and $10 \mu \mathrm{g}$ once daily. ${ }^{15,35}$

To our knowledge, this study represents one of the largest and most detailed databases of Holter ECG data in COPD involving 775 patients - and benefits from the availability of baseline and follow-up data for multiple defined time points and treatment groups. Furthermore, the Holter monitoring enables accurate collection of 24-hour heart rate data during both rest and daily activity. Nevertheless, this analysis also has some limitations. Study sites that were not able to perform Holter ECGs and patients who were not capable of carrying the device were not included in the analysis. Therefore, the subset of patients included in this analysis were not selected at random. At baseline, the Holter subset was representative of the full study population in terms of $\mathrm{CV}$ medication but had a slightly higher incidence of arrhythmia. The small difference in cardiac arrhythmia may be explained by the fact that patients in the Holter subset were being treated at specialist hospitals more likely to detect arrhythmia or that they volunteered to be screened as they were familiar with the equipment from previous screening. Additionally, around half of the patients included in the Holter analysis who were treated with a LABA during the trial were receiving LABA therapy at baseline. Previous studies have suggested that an increased risk of $\mathrm{CV}$ disease is limited to the initiation of inhaled
LABA therapy; ${ }^{36}$ however, due to the nature of this post hoc analysis, we are unable to investigate whether prior medication had any effect on outcomes. The current post hoc analysis provides useful data in addition to the current literature; however, to detect statistically significant differences of this small magnitude would require a larger study population. Furthermore, although this is a large database, the sample size did not allow reliable detection of differences in rare events such as ventricular tachycardia or sudden cardiac death. Patients with more unstable CV diseases may have been excluded from the trials and subsequent Holter ECG subset. Therefore, further work is needed to study patients with more unstable $\mathrm{CV}$ diseases. In this post hoc analysis, the larger treatment groups were broadly well balanced; however, by chance, the smaller formoterol group had fewer cardiovascular risk factors. Despite this, we do not feel that this imbalance has impacted the results of this study.

\section{Conclusions}

These data provide reassurance for clinicians that longterm treatment with olodaterol or formoterol, as assessed by Holter ECG, is associated with neither an increased risk of cardiac arrhythmias nor a major impact on heart rate in patients with GOLD 2-4 COPD.

\section{Abbreviations}

$\mathrm{AR}$, adrenoreceptor; $\mathrm{AUC}_{0-3}$, area under the curve 3 hours post-dose; bpm, beats per minute; COPD, chronic obstructive pulmonary disease; $\mathrm{CV}$, cardiovascular; DPI, dry powder inhaler; ECG, electrocardiogram; $\mathrm{FEV}_{1}$, forced expiratory volume in 1 second; GOLD, Global Initiative for Chronic Obstructive Pulmonary Disease; LABA, long-acting $\beta_{2^{-}}$ agonist; MACE, major adverse cardiovascular event; SMI, Soft Mist ${ }^{\mathrm{TM}}$ inhaler; SVPB, supraventricular premature beat; VPB, ventricular premature beat.

\section{Data Sharing Statement}

Boehringer Ingelheim is committed to responsible sharing of clinical study reports, related clinical documents, and patient-level clinical study data. Researchers are invited to submit enquiries via the Clinical Study Data Request website (https://www.clinicalstudydatarequest.com).

\section{Ethics Approval and Consent to Participate}

All studies included in this analysis were performed in accordance with the provisions of the Declaration of Helsinki (1996 
version), the International Conference on Harmonisation Tripartite Guideline for Good Clinical Practice, and local regulations. The protocol was approved by the ethics research boards of the respective institutions, applicable regulatory requirements and Boehringer Ingelheim Standard Operating Procedures. A full list of participating sites in the studies included in this analysis is included in the supplementary file (Supplementary Table 2), and can be found at https://clinical trials.gov/ct2/show/NCT00782210, https://clinicaltrials.gov/ ct2/show/NCT00782509, https://clinicaltrials.gov/ct2/show/ NCT00793624 and https://clinicaltrials.gov/ct2/show/ NCT00796653. All patients provided written informed consent. This article does not report individual patient data; all data presented here are anonymized. The clinical trial protocols and the informed consent and patient information forms were reviewed and received approval/favorable opinion from a constituted local Institutional Review Board or an Independent Ethics Committee at each center prior to the start of the study.

\section{Acknowledgments}

All authors take responsibility for all aspects of the reliability and freedom from bias of the data presented and their discussed interpretation.

\section{Author Contributions}

All the authors have made substantial contributions to study design, data acquisition, analysis or interpretation, drafting the article, or critically revising the content, provided final approval of the version to be published, and agree to be accountable for all aspects of the work.

\section{Funding}

This work was supported by Boehringer Ingelheim International $\mathrm{GmbH}$. Medical writing assistance, in the form of the preparation and revision of the manuscript, was supported financially by Boehringer Ingelheim, and provided by Lucia Massi of MediTech Media (London, UK) under the authors' conceptual direction and based on feedback from the authors.

\section{Disclosure}

SA reports personal fees from Boehringer Ingelheim and GlaxoSmithKline, and payments for presenting from Boehringer Ingelheim, AstraZeneca, Berlin Chemie, Chiesi and Novartis, outside the submitted work. UB, AdlH, IK and MT are employees of Boehringer Ingelheim. PA reports grants from the German Federal Ministry of Education and Research (BMBF) Competence Network Asthma and COPD (ASCONET), AstraZeneca, GlaxoSmithKline, Grifols Deutschland, MSD Sharp \& Dohme, Pfizer, Takeda, Boehringer Ingelheim and Novartis Deutschland, grants and non-financial support from Bayer Schering Pharma AG and Chiesi, grants, personal fees and non-financial support from Novartis Deutschland, and grants and personal fees from Novartis Deutschland, outside the submitted work. The authors report no other conflicts of interest in this work.

\section{References}

1. Alter P, Mayerhofer B, Kahnert K, et al. Prevalence of cardiac comorbidities, and their underdetection and contribution to exertional symptoms in COPD: results from the COSYCONET cohort. Int J Chron Obstruct Pulmon Dis. 2019;14:2163-2172. doi:10.2147/COPD.S209343

2. Global Initiative for Chronic Obstructive Lung Disease. Global strategy for the diagnosis, management, and prevention of chronic obstructive pulmonary disease (2020 report). Published 2019. Available from: https://goldcopd.org/wp-content/uploads/2019/11/ GOLD-2020-REPORT-ver1.0wms.pdf. Accessed February 14, 2020.

3. Feary JR, Rodrigues LC, Smith CJ, Hubbard RB, Gibson JE. Prevalence of major comorbidities in subjects with COPD and incidence of myocardial infarction and stroke: a comprehensive analysis using data from primary care. Thorax. 2010;65(11):956-962. doi:10.1136/thx.2009.128082

4. Cazzola M, Calzetta L, Bettoncelli G, et al. Cardiovascular disease in asthma and COPD: a population-based retrospective cross-sectional study. Respir Med. 2012;106(2):249-256. doi:10.1016/j. rmed.2011.07.021

5. Cazzola M, Rogliani P, Matera MG. Cardiovascular disease in patients with COPD. Lancet Respir Med. 2015;3(8):593-595. doi:10.1016/S2213-2600(15)00279-9

6. Janssen O, Schaumann F, Holz O, et al. Low-dose endotoxin inhalation in healthy volunteers-a challenge model for early clinical drug development. BMC Pulm Med. 2013;13(1):19. doi:10.1186/14712466-13-19

7. Hawkins NM, Huang Z, Pieper KS, et al. Chronic obstructive pulmonary disease is an independent predictor of death but not atherosclerotic events in patients with myocardial infarction: analysis of the Valsartan in Acute Myocardial Infarction Trial (VALIANT). Eur J Heart Fail. 2009;11(3):292-298. doi:10.1093/ eurjhf/hfp001

8. Sin DD, Anthonisen NR, Soriano JB, Agusti AG. Mortality in COPD: role of comorbidities. Eur Respir J. 2006;28(6):1245-1257. doi:10.1183/09031936.00133805

9. Cazzola M, Imperatore F, Salzillo A, et al. Cardiac effects of formoterol and salmeterol in patients suffering from COPD with preexisting cardiac arrhythmias and hypoxemia. Chest. 1998;114 (2):411-415. doi:10.1378/chest.114.2.411

10. Boehringer Ingelheim International GmbH. Striverdi Respimat 2.5 microgram, solution for inhalation - summary of product characteristics, Europe. Published 2019. Available from: https://www.medi cines.org.uk/emc/product/3255/smpc. Accessed December 4, 2019.

11. Chen Y-F, Cheng Y-C, Chou C-H, Chen C-Y, Yu C-J. Major comorbidities lead to the risk of adverse cardiovascular events in chronic obstructive pulmonary disease patients using inhaled long-acting bronchodilators: a case-control study. BMC Pulm Med. 2019;19 (1):233. doi:10.1186/s12890-019-0999-z 
12. Salpeter SR, Ormiston TM, Salpeter EE. Cardiovascular effects of $\beta$ agonists in patients with asthma and COPD. Chest. 2004;125 (6):2309-2321. doi:10.1378/chest.125.6.2309

13. Andreas S, Bothner U, Trampisch M, Haensel M, Buhl R, Alter P. Effect of long-acting $\beta 2$-agonists olodaterol and formoterol on heart rate and blood pressure in chronic obstructive pulmonary disease patients. Pulm Pharmacol Ther. 2018;52:1-6. doi:10.1016/j.pupt.2018.08.002

14. Rabe KF, Hurst JR, Suissa S. Cardiovascular disease and COPD: dangerous liaisons? Eur Respir Rev. 2018;27(149):pii:180057. doi:10.1183/16000617.0057-2018

15. Matera MG, Ora J, Cazzola M. Differential pharmacology and clinical utility of long-acting bronchodilators in COPD - focus on olodaterol. Ther Clin Risk Manag. 2015;11:1805-1811. doi:10.2147/TCRM.S73581

16. Handley DA, Morley J. The pursuit of precision pharmaceuticals: divergent effects of $\beta 2$ agonist isomers. Expert Opin Investig Drugs. 1998;7(10):1601-1616. doi:10.1517/13543784.7.10.1601

17. Ramsay CM, Cowan J, Flannery E, McLachlan C, Taylor DR. Bronchoprotective and bronchodilator effects of single doses of (S)-salbutamol, (R)-salbutamol and racemic salbutamol in patients with bronchial asthma. Eur J Clin Pharmacol. 1999;55(5):353-359. doi:10.1007/s002280050640

18. Ferguson GT, Feldman GJ, Hofbauer P, et al. Efficacy and safety of olodaterol once daily delivered via Respimat ${ }^{\circledR}$ in patients with GOLD 2-4 COPD: results from two replicate 48-week studies. Int J Chron Obstruct Pulmon Dis. 2014;9:629-645. doi:10.2147/COPD.S61717

19. Koch A, Pizzichini E, Hamilton A, et al. Lung function efficacy and symptomatic benefit of olodaterol once daily delivered via Respimat ${ }^{\circledR}$ versus placebo and formoterol twice daily in patients with GOLD 2-4 COPD: results from two replicate 48-week studies. Int J Chron Obstruct Pulmon Dis. 2014;9:697-714. doi:10.2147/COPD.S62502

20. McGarvey L, Niewoehner D, Magder S, et al. One-year safety of olodaterol once daily via Respimat ${ }^{\circledR}$ in patients with GOLD 2-4 chronic obstructive pulmonary disease: results of a pre-specified pooled analysis. COPD. 2015;12(5):484-493. doi:10.3109/15412555.2014.991864

21. Alter P, Watz H, Kahnert K, et al. Airway obstruction and lung hyperinflation in COPD are linked to an impaired left ventricular diastolic filling. Respir Med. 2018;137:14-22. doi:10.1016/j.rmed.2018.02.011

22. Watz H, Waschki B, Meyer T, et al. Decreasing cardiac chamber sizes and associated heart dysfunction in COPD: role of hyperinflation. Chest. 2010;138(1):32-38. doi:10.1378/chest.09-2810

23. Hohlfeld JM, Vogel-Claussen J, Biller H, et al. Effect of lung deflation with indacaterol plus glycopyrronium on ventricular filling in patients with hyperinflation and COPD (CLAIM): a double-blind, randomised, crossover, placebo-controlled, single-centre trial. Lancet Respir Med. 2018;6(5):368-378. doi:10.1016/S2213-2600(18)30054-7

24. Raupach T, Bahr F, Herrmann P, et al. Slow breathing reduces sympathoexcitation in COPD. Eur Respir J. 2008;32(2):387-392. doi:10.1183/09031936.00109607

25. Maltais F, O'Donnell D, Galdiz Iturri JB, et al. Effect of 12 weeks of once-daily tiotropium/olodaterol on exercise endurance during constant work-rate cycling and endurance shuttle walking in chronic obstructive pulmonary disease. Ther Adv Respir Dis. 2018;12:1-13. doi: $10.1177 / 1753465818755091$
26. Berton DC, Barbosa PB, Takara LS, et al. Bronchodilators accelerate the dynamics of muscle $\mathrm{O} 2$ delivery and utilisation during exercise in COPD. Thorax. 2010;65(7):588-593. doi:10.1136/thx.2009.120857

27. Lahousse L, Verhamme KM, Stricker BH, Brusselle GG. Cardiac effects of current treatments of chronic obstructive pulmonary disease. Lancet Respir Med. 2016;4(2):149-164. doi:10.1016/S2213-2600(15)00518-4

28. Galli A, Ambrosini F, Lombardi F. Holter monitoring and loop recorders: from research to clinical practice. Arrhythm Electrophysiol Rev. 2016;5(2):136-143. doi:10.15420/AER.2016.17.2

29. Priori SG, Blomström-Lundqvist C, Mazzanti A, et al. 2015 ESC Guidelines for the management of patients with ventricular arrhythmias and the prevention of sudden cardiac death: the task force for the management of patients with ventricular arrhythmias and the prevention of sudden cardiac death of the European Society of Cardiology (ESC) Endorsed by: Association for European Paediatric and Congenital Cardiology (AEPC). EP Europace. 2015;17(11):1601-1687. doi:10.1093/europace/euv319

30. Incorvaia C, Montagni M, Makri E, Riario-Sforza GG, Ridolo E. Striving for optimal bronchodilation: focus on olodaterol. Int J Chron Obstruct Pulmon Dis. 2016;11:439-444. doi:10.2147/COPD.S96070

31. Watz H, Troosters T, Beeh KM, et al. ACTIVATE: the effect of aclidinium/formoterol on hyperinflation, exercise capacity, and physical activity in patients with COPD. Int J Chron Obstruct Pulmon Dis. 2017;12:2545-2558. doi:10.2147/COPD.S143488

32. Nelson HS, Gross NJ, Levine B, et al. Cardiac safety profile of nebulized formoterol in adults with COPD: a 12-week, multicenter, randomized, double- blind, double-dummy, placebo- and active-controlled trial. Clin Ther. 2007;29(10):2167-2178. doi:10.1016/j.clinthera.2007.10.007

33. Borghardt JM, Kloft C, Sharma A. Inhaled therapy in respiratory disease: the complex interplay of pulmonary kinetic processes. Can Respir J. 2018;2018:2732017. doi:10.1155/2018/2732017

34. Bouyssou T, Hoenke C, Rudolf K, et al. Discovery of olodaterol, a novel inhaled $\beta 2$-adrenoceptor agonist with a $24 \mathrm{~h}$ bronchodilatory efficacy. Bioorg Med Chem Lett. 2010;20(4):1410-1414. doi:10.1016/j.bmcl.2009.12.087

35. Maleki-Yazdi MR, Beck E, Hamilton AL, Korducki L, Koker P, Fogarty C. A randomised, placebo-controlled, phase II, doseranging trial of once-daily treatment with olodaterol, a novel longacting $\beta 2$-agonist, for 4 weeks in patients with chronic obstructive pulmonary disease. Respir Med. 2015;109(5):596-605. doi:10.1016/j. rmed.2015.02.012

36. Wang M-T, Liou J-T, Lin CW, et al. Association of cardiovascular risk with inhaled long-acting bronchodilators in patients with chronic obstructive pulmonary disease: a nested case-control study. JAMA Intern Med. 2018;178(2):229-238. doi:10.1001/jamainternmed.2017.7720

\section{Publish your work in this journal}

The International Journal of COPD is an international, peer-reviewed journal of therapeutics and pharmacology focusing on concise rapid reporting of clinical studies and reviews in COPD. Special focus is given to the pathophysiological processes underlying the disease, intervention programs, patient focused education, and self management protocols. This journal is indexed on PubMed Central, MedLine and CAS. The manuscript management system is completely online and includes a very quick and fair peer-review system, which is all easy to use. Visit http://www.dovepress.com/testimonials.php to read real quotes from published authors. 